\title{
Fenomenologia e Esquizoanálise na Psicologia: UM ENCONTRO PoSSÍvel?
}

\author{
Reinaldo Furlan ${ }^{1}$ \\ Faculdade de Filosofia, Ciências e Letras de Ribeirão Preto - USP
}

\begin{abstract}
Nossa intenção é aproximar duas importantes áreas da Filosofia - a fenomenologia e a esquizoanálise - presentes no campo da Psicologia enquanto formas ou perspectivas de pesquisa. Acreditamos que o encontro crítico dessas filosofias possa trazer ganhos de diferentes espécies, desde uma melhor compreensão de seus sentidos, até uma ampliação do horizonte do uso que se faz delas no campo da Psicologia.

Descritores: Fenomenologia. Esquizoanálise. Merleau-Ponty, Maurice, 1908-1961. Foucault, Michel, 1926-1984. Deleuze, Gilles, 1925-1995.
\end{abstract}

\begin{abstract}
perspectiva das análises de Foucault sobre o saber e o poder tem sido Autilizada na Psicologia para diagnóstico de contextos de vida individual e coletiva. Das filosofias de Heidegger, Sartre e Merleau-Ponty, surgiu o que se chama, de modo geral, psicologia fenomenológica, ou de inspiração fenomenológica. A esquizoanálise, de Deleuze e Guattari, por definição, é uma proposta de intervenção política, que implica os saberes psicológicos. De modo que não é difícil constatar a presença dessas filosofais na Psicologia atual. Mas, mais do que apontar para a importância desses pensamentos nas pesquisas em Psicologia, importa discutir suas diferenças e semelhanças, pois tratam da construção de um saber que organiza determinado tipo de olhar e intervenção na realidade. Creio que o encontro crítico dessas filosofias possa trazer ganhos
\end{abstract}

1 Docente do Departamento de Psicologia e Educação da Faculdade de Filosofia, Ciências e Letras de Ribeirão Preto - USP. Endereço para correspondência: Av. Bandeirantes, 3900 - Monte Alegre, Ribeirão Preto - São Paulo. CEP 14040-901. Endereço eletrônico: reinaldof@ ffclrp.usp.br 
de diferentes espécies, inclusive de melhor compreensão do sentido de cada uma em suas diferenças, mas também de ampliação de seus horizontes, em particular, no uso que delas se faz no campo da Psicologia. Mais do que discutir a fundo a relação das filosofias desses autores, o que não seria possível nos limites desse artigo, pretendemos iniciar um debate entre essas perspectivas que, em geral, são assumidas por pesquisadores na Psicologia de forma unilateral, ou dar início a uma comparação, do ponto de vista teórico e metodológico, e suas consequiências para a Psicologia, entre a fenomenologia de Merleau-Ponty e a esquizoanálise de Deleuze e Guattari, bem como de suas ligações com os trabalhos desenvolvidos por Foucault, também devotados a uma análise crítica das ciências humanas. É sabido, nesse sentido, que Deleuze (1986/1998) lhe dedica um livro (Foucault), não somente como manifesto de simpatia e admiração por seu trabalho, mas como parte de uma perspectiva de pensamento comum frente aos pensamentos de Heidegger e de Merleau-Ponty.

Não se trata, pois, de fazer uma comparação rigorosa entre essas filosofias, nem mesmo de noções centrais ou termos que aparentemente parecem suscitar diferenças evidentes, mas que podem ter um funcionamento semelhante nessas filosofias. É o caso, por exemplo, da noção de "profundidade" em Merleau-Ponty, a que parece se opor a noção de "superficialidade", privilegiada pelas filosofias de Deleuze e Guattari e de Foucault, quando essas noções aparentemente opostas querem dizer, em primeiro lugar, que o sentido das coisas está em suas relações com as outras. Também há termos cuja correspondência parece imediata, e que suscitam a questão sobre suas diferenças, como, por exemplo, a relação entre corpo efetivo e corpo fenomenal na filosofia de Merleau-Ponty, e a relação entre organismo e corpo sem órgãos na filosofia de Deleuze-Guattari, ou, respectivamente, entre os termos "sedimentação" e "estratificação", "expressão" e "materialismo incorpóreo", e as noções de "virtual" e de "memória", centrais em suas filosofias. Não é possível fazer esse levantamento aqui. Queremos apenas sugerir uma primeira aproximação, e se conseguirmos ao menos romper o isolamento entre essas perspectivas de pesquisa na Psicologia (em geral, da fenomenologia em relação à esquizoanálise), ou a apropriação unilateral de uma sobre a outra (em geral, da esquizoanálise sobre a fenomenologia $)^{2}$, teremos conseguido nosso objetivo.

2 Nesse caso, favorecida pelas posturas de Foucault e de Deleuze em relação à fenomenologia. Em geral, pesquisadores de perspectiva fenomenológica ignoram ou 
É sabido que a fenomenologia se propõe como uma investigação que procura dizer o sentido das coisas mesmas, e que se trata de descrever e não de explicar o sentido percebido. Aparentemente, nada mais contrário ao princípio da esquizoanálise de que ver e dizer já é compor com a realidade, de que não há formas de sentido preestabelecidas ou naturais, e por isso não pode haver fenomenologia, mas apenas políticas, sempre no plural, cujas composições são formas atuais da realidade, sempre em devir pelo excesso mesmo das forças que as ultrapassam. Trata-se, então, sempre de conceber as formas de sentido a partir da ação de forças que as compõem. Ora, esse é um dos pontos de partida da fenomenologia de Merleau-Ponty, que concebe já a visão como uma forma de agir através da qual o corpo se reúne para tomar posse do mundo. A visão se funda na motricidade do corpo, que, por sua vez, se serve da prospecção do olhar para o próprio movimento. Se Merleau-Ponty diz que não há o caos, é porque o pensamento já encontra realizado um sentido de mundo organizado na experiência do corpo próprio, sentido mais antigo que o pensamento e, portanto, opaco à reflexão, e é por isso que o caos, em Deleuze-Guattari só pode ser pensado junto ao sentido que se encontra sempre de alguma forma realizado. Também o dizer na fenomenologia de Merleau-Ponty não encerra a aparente inocência que a noção de redução fenomenológica parece ter; é preciso saber temperar sua fenomenologia com a de Hegel, encarnada pelo marxismo e batizada de contingência pelo existencialismo do próprio Merleau-Ponty. ${ }^{3}$ Dizer é fazer, e a experiência é insubstituível, e no entanto ou por essa mesma razão, a verdade é possível. Vale citar o próprio Merleau-Ponty (1945/1994):

A verdadeira filosofia é reaprender a ver o mundo, e nesse sentido uma história narrada pode significar o mundo com tanta 'profundidade' quanto um tratado de filosofia. Nós tomamos em nossas mãos o nosso destino, tornamo-nos responsáveis, pela reflexão, por nossa história, mas também graças a uma decisão em que empenhamos nossa vida, e nos dois casos trata-se de um ato violento que se verifica exercendo-se. (p. 19)

E se o modo como termina um livro ou ensaio muitas vezes revela uma de suas intenções principais, Merleau-Ponty encerra a Fenomenologia

não reconhecem a esquizoanálise, e pesquisadores de perspectiva esquizoanalítica ignoram a contribuição da fenomenologia, dada por realizada a crítica de Foucault e de Deleuze e Guattari à mesma.

3 O Hegel de 1808, anterior à Lógica e ao Sistema em que terminou sua filosofia. 
da Percepção com uma citação de Saint-Exupéry: "O homem é só um laço de relações, apenas as relações contam para o homem” (1945/1994, p. 612).

Também é revelador, nesse sentido, a importância da Psicanálise em sua obra, por meio da qual o autor procura mostrar a presença do outro em nós ou a invasão de um no outro, o que porta sempre também um caráter de força, de violência ou sedução.

Com isso não queremos dizer que toda a crítica de Deleuze e Guattari à fenomenologia seja um equívoco, ao menos na figura de Merleau-Ponty, mais próxima a eles, ou que semânticas aparentemente tão diferentes não revelem diferenças fundamentais, a despeito de também poderem ocultar semelhanças ou proximidades importantes. Na verdade, pensamos que este é um balanço que ainda precisa ser feito, aquém das antinomias das políticas universitárias ou das escolas filosóficas, pois há certo exagero de retórica e alguns golpes baixos nas penas de Deleuze e Guattari e de Foucault na contenda de suas filosofias com a fenomenologia, que nelas aparece, às vezes, de forma muito caricatural. Ao lado de análises brilhantes ou merecedoras de atenção - como as de Foucault (1966/1999) sobre as filosofias da analítica da finitude em As Palavras e as Coisas (que, aliás, parece tomar por modelo ou sua expressão mais acabada os primeiros trabalhos de Merleau-Ponty), e de Deleuze e Guattari (1991/1992) sobre a fenomenologia em O que é a Filosofia? -, também encontramos críticas que se utilizam da imagem mais comum de fenomenologia que, mesmo apoiada nos textos mais canônicos de Husserl, não vale para toda a escola; ou críticas muito parciais sobre o pensamento de MerleauPonty, talvez porque seja a herança mais próxima de suas filosofias; ou que reconhecem a importância de Heidegger, como se o mesmo não tivesse nada a ver com a história da fenomenologia. Por exemplo, a referência implícita de Foucault (1971/2000b) à fenomenologia de Merleau-Ponty em A Ordem do Discurso, a respeito do tema da experiência originária, que aponta para a presença de sentidos murmurantes no mundo percebido, que a linguagem pode manifestar através de discreta leitura, com o que, segundo Foucault, a Filosofia se esquiva do acontecimento e da materialidade do discurso. Com muito boa vontade, essa crítica só pode ser muito parcial. Nesse sentido, o que diz Foucault (1966/1994a) em La Pensée du Dehors, em tese, que o pensamento se realiza na linguagem, portanto, do lado de fora, e que encontra paralelo em 
As Palavras e as Coisas (Foucault, 1966/1999) na concepção de linguagem da literatura moderna, encontra-se fartamente afirmado na filosofia de MerleauPonty. Mas o que Foucault (1970/1994b, pp. 75-99) escreveu a respeito da fenomenologia de Sartre e Merleau-Ponty em Theatrum Philosophicum, junto a uma análise esclarecedora de Diferença e Repetição (Deleuze, 1968/2000), só pode ser compreendido do ponto de vista político, é mistificação.

A tentativa de um balanço mais honesto e generoso com os pensamentos de Heidegger e Merleau-Ponty encontramos em Deleuze (1986/1998), sobretudo no capítulo "As Dobras da Subjetivação", em seu Foucault.

Pretendemos fazer a aproximação dessas filosofias por meio da discussão da complexidade de algumas questões presentes na Psicologia. Mais precisamente, a partir da questão da intersubjetividade, que a uma só vez remete à singularidade do indivíduo e ao seu ser genérico ou social, ou ao campo da memória e do presente atual. Abordamos essas questões por meio da relação entre as dimensões macro e micro de sentidos, e da noção de figura e fundo, que por fim desembocam na questão crucial a toda filosofia, mas também implícita em toda perspectiva de pesquisa: o que é ver, dizer, ou qual a relação entre ver e dizer?

\section{As relações "macro" e "micro" de sentidos}

A complexidade de algumas questões em Psicologia encontra-se na relação entre as dimensões macro e micro de sentidos que elas envolvem. Em certo sentido, pode-se considerar essa distinção como sendo abstrata. Essa discussão já apareceu em Sartre (1960/1979) como herdeira do marxismo, que, por sua vez, a herdou de Hegel. A questão é mais ou menos esta, em Questão de Método (Sartre, 1960/1979): existe um universal e um particular que não expressam a realidade concreta do homem; de um lado, temos generalidades vazias, em que falta justamente a dimensão do particular, das situações e dos indivíduos com suas singularidades, tensões, contradições, afetos etc. (do aqui e agora, como se costuma dizer), e, de outro lado, particularidades também vazias, em que a realidade individual do homem se perde no vazio de uma subjetividade abstrata, onde falta, justamente, a dimensão social da sua realidade, que também implica a duração de um tempo mais longo. 
Sartre (1960/1979), neste ensaio, aceita a concepção marxista de "totalização" do sentido da realidade histórico-social, expressa com suas noções de "modo de produção", "relações de classes", "dialética" etc., como o conhecimento de nossa época, que não seria superado enquanto as condições de vida do capitalismo não fossem superadas. Mas dizia que, a despeito disso, saberes menores e dependentes, como o existencialismo, continuavam a operar porque olhavam para uma dimensão de sentido que o marxismo "preguiçoso" não considerava (justamente o particular, o individual). Os marxistas de sua época, segundo Sartre, repetiam discursos gerais sobre os fatos e não mergulhavam na riqueza do concreto, onde o acontecimento e a história se faz.

Merleau-Ponty também se aproximou da teoria marxista, e assim como Sartre, enfatizou muito a importância de descrições atentas às particularidades para análises concretas dos fatos, porém, não comungava com Sartre a crença no princípio marxista de totalização do sentido da realidade. Há uma longa nota sobre o materialismo histórico em Fenomenologia da Percepção (MerleauPonty, 1945/1994), ao fim do capítulo "O Corpo como Ser Sexuado", em que Merleau-Ponty procura integrar a visão marxista da história numa noção mais ampla de Existência. A saber, assim como Freud trouxe a noção de "sexualidade" para a existência, focando a história da libido na relação com o outro para a compreensão da sexualidade e da vida do homem, quando a sexualidade era considerada, até então, como tendo apenas uma história biológica, também Marx trouxe a noção de "economia" para a história, quando a economia era considerada, até então, subproduto do palco das decisões políticas, do desenvolvimento das idéias e descobertas técnico-científicas.

Segundo Merleau-Ponty, há sempre muitas relações em jogo, e estruturações de sentidos que parecem dominantes em determinada etapa da pesquisa podem se revelar, depois, menos importantes do que outras. É para o que aponta a noção de "dialética instável", que Merleau-Ponty (1964/2000a, pp. 93-96) discute em $O$ Visível e o Invisível:

a verdadeira dialética é aquela que aceita rever ou modificar seus pressupostos iniciais, conforme o desenvolvimento da pesquisa, ao invés de apenas desdobrar um sentido cujo movimento é de antemão possuído em tese. A verdadeira dialética, diz Merleau-Ponty aí, não pode se afirmar em teses, expressa mais um movimento de pensamento do que propriamente um saber determinado. 
Este caráter mais aberto e indefinido de sentidos também se encontra em Foucault, sobretudo em sua fase genealógica que, se privilegia o tema do poder, trata de múltiplas relações de poderes, cujos arranjos histórico-sociais dependem sempre de micropolíticas e estratégias instáveis.

Foucault (1969/2000a, pp. 11-12) recusa a concepção marxista de História, que inclui como parte do que chama de concepção de "História Global", em troca de uma concepção de "História Geral". Enquanto a primeira obedece a um princípio organizador de sentido que ilumina todos os acontecimentos, isto é, que compreende os acontecimentos sob uma lógica dominante ou unificadora, a segunda compreende diferentes séries de produções de sentidos formadas em tempos sociais diferentes, que coexistem num mesmo espaço social, compondo-se, modificando-se ou se apagando em suas relações; enfim, um conjunto de práticas e sentidos que fazem do conjunto social uma "totalidade" mais heterogênea ou mais complexa que a unidade de sentido que uma "história global" apresenta.

Ora, analisando o movimento das filosofias reflexivas (Descartes e Kant), Merleau-Ponty usa Hegel para encaminhar a solução da questão da relação entre o particular e o universal (conforme os termos de Questão de Método), bem como a superação da dicotomia entre interioridade e exterioridade: precisamos compreender que "entrar em si também é sair de si" (Merleau-Ponty, 1964/2000a, p. 56), ou seja, "entrar em si” é se compreender, mas eu só me compreendo nas relações, porque sou fora, no mundo, e, portanto, só me conheço aí. Por isso todas as pesquisas histórico-sociais (Foucault e Marx, por exemplo) não são contraditórias com o sentido da vida que vivemos por contato (que seria a perspectiva da "interioridade", que não contraria, pois, o primado da exterioridade). Mas, posto isso, o importante é não "jogar a criança com a água do banho", pois, afinal, se tudo é "fora" - se somos na relação com as coisas e os outros, se a felicidade que sinto, como diz um poema de Fernando Pessoa, é algo que não me pertence, pois é no mundo, na minha relação com o outro, como a luz do sol "que me bate na cara e me ofusca" (Pessoa, 1946/2004, p. 155) -, esse "fora" não é um espaço que desfaz nossas diferenças ou subjetividades, mas espaço de comunicação e transição de um sentido ao outro. Somos um para o outro, a tal ponto que o outro também está em mim e eu estou no outro, como insistia Merleau-Ponty (1988, 1995/2000b, 1996), 
apontando, por exemplo, como a psicanálise de Freud passou progressivamente da oposição entre dentro (id) e fora (realidade), para a concepção de uma relação constitutiva e promíscua entre os termos, em que o fora também está dentro, e o dentro também está fora (projeção - introjeção, conforme a Psicanálise). Eu e o outro somos no mundo e é no mundo que nos encontramos.

Mais ainda, Merleau-Ponty (1964/2000a) nota, com precisão, que a questão da relação com o outro ainda é uma forma de colocar o problema a partir da temática da consciência, e que é mais apropriado dizer que se trata da questão da relação com os outros, porque a relação com o outro passa, no mínimo, por um terceiro, como mostra a Psicanálise, que representa de forma clara o estatuto social da relação com o outro que, no caso da relação da criança com a mãe, passa pela relação com o pai.

Merleau-Ponty (1996) fala em "magma ou promiscuidade dos homens no mundo" (p. 204), de invasão dos sentidos de um sobre o outro ou de constituição recíproca dos sentidos - o que chamamos intersubjetividade, que podemos destacar a partir da experiência do olhar:

Esta mistura e esta invasão (de um sobre o outro) existem já porque nós vemos, isto é, vemos os outros verem, com uma sutileza extraordinária, vemos com os olhos dos outros desde que tenhamos olhos (...) Isso parece $6^{\circ}$ sentido porque cremos que se vê apenas coisas visíveis ou qualidades: mas eu vejo corpos dirigidos para o mundo e para o mesmo mundo que eu vejo, seus gestos ínfimos, eu os esposo, eu os vejo do interior. Os homens também são homens-gignognes ${ }^{4}$ - Se se pudesse abrir um, nele encontraríamos todos os outros como nas bonecas russas, ou antes, menos bem ordenados, em um estado de indivisão. (1996, p. 211)

Em outros termos, o olhar é uma variação privilegiada da experiência da "carne" em geral, conforme a análise merleaupontyana da imagem especular do corpo:

Schilder observa: fumando cachimbo diante do espelho, sinto a superfície lisa e ardente da madeira não somente lá onde estão meus dedos, mas também nesses dedos gloriosos, nesses dedos apenas visíveis que estão no fundo do espelho. O fantasma do espelho arrasta para fora minha carne, e, do mesmo passo, todo o invisível de meu corpo pode investir os outros corpos que vejo. Doravante, meu

4 Referência à personagem do teatro infantil que se apresenta como mãe de muitos filhos, que lhe saem debaixo das saias. 
Fenomenologia e Esquizoanálise na Psicologia: um Encontro Possível?

corpo pode comportar segmentos extraídos dos outros como minha substância se transfere para eles: o homem é espelho para o homem. Quanto ao espelho, ele é o instrumento de uma universal magia que transforma coisas em espetáculos, os espetáculos em coisas, eu no outro e o outro em mim. (1960/1984a, p. 93)

Assim se funda a comunicação com o outro e o processo de constituição de nossas identidades. Pode-se dizer, por exemplo, que o bebê se identifica com a mãe que ele vê antes da própria imagem (no espelho) e, nesse sentido, que "o bebê é a mãe", ou que "o eu é o outro". Mas a imagem da mãe incorporada ("introjeção") no processo de identificação do bebê, não é a única operação de sentido na relação mãe-bebê, pois também há migração ("projeção") da "carne" do bebê na percepção da mãe, isto é, de sua propriocepção para o sentido (ou "carne") da mãe que ele percebe, e que, portanto, também a constitui ou faz parte da sua identidade para o bebê, como no exemplo citado de Schilder. E, nesse caso, pode-se dizer que "o outro é o eu". De tal forma que eu e o outro formamos um sistema.

\section{A noção "figura e fundo"}

Outro exemplo da complexidade de algumas questões em Psicologia encontra-se na relação entre as noções de "figura e fundo", que Merleau-Ponty toma da Psicologia da Forma para descrever a abertura de nosso sentido de mundo. Quando se diz que a estrutura mais elementar da percepção é a relação figura e fundo, com isso se abandona a idéia de que o dado mais elementar da percepção é um conjunto de estímulos que, de alguma forma, devem ser associados para a composição do sentido da visão, e se afirma a presença originária de um sentido que é na relação ou diferença com outro. Por exemplo, se vejo o ponto branco, é porque ele se destaca, isto é, se diferencia do fundo que é de outra cor, e o mundo passa a ser um sistema de diferenças de sentidos que se reenviam.

Por isso Merleau-Ponty diz que a Psicologia da Forma possui o segredo do espírito, desde que devidamente interpretada, pois apreende o espírito situado no mundo. Ou seja, faz parte do sentido percebido e da palavra compreendida um fundo de visibilidade e sensibilidade que não vejo ou sinto, e de linguagem que não pronuncio ou escuto, no sentido restrito dos termos, mas 
que participam como condição do sentido do que vejo, sinto e compreendo (o fundo da percepção ou a língua que trago como horizontes de mundo, o que significa a participação da totalidade na singularidade, conforme os termos da discussão anterior). Por exemplo, quando conversamos ou lemos um livro, toda a linguagem que aprendemos participa como fundo, como um horizonte que possuímos e faz parte disso que falamos e compreendemos; quando percebemos ou nos movimentamos, o mundo que nos é habitual com certo esquema motor participa enquanto fundo da percepção e do movimento: nosso senso de equilíbrio, das relações espaciais - adiante e atrás, direito e esquerdo, alto e baixo -, das experiências de peso, odor, tamanho e distância etc. São experiências de mundo que trazemos junto ao corpo (fenomenal) e não às lembranças do pensamento, como a memória que, dizia Proust (1913/1987), trago nas pernas, no cheiro das coisas ou no gosto da madeleine na boca. Por isso, entre o intelectualismo e o objetivismo, isto é, entre a interpretação do pensamento e a ação causal de um objeto sobre outro - que são as alternativas cartesianas de concepção da realidade (existência enquanto pensamento ou coisa) -, trata-se de recuperar o sentido do mundo fenomenal. Do intelectualismo cartesiano pode nascer uma Psicologia cognitivista que supõe sempre um ato de interpretação do pensamento sobre a realidade; do objetivismo cartesiano pode nascer uma Psicologia Behaviorista, desde que o Behaviorismo termine, como a Psicologia da Forma, reduzindo a relação do organismo com o meio a relações fisiológicas determinadas, ao invés de concebê-las a partir do próprio comportamento, como sugeria Goldstein. É essa alternativa que a fenomenologia de Merleau-Ponty procura romper apoiando-se no sentido dos próprios trabalhos da Psicologia.

Mas se Merleau-Ponty descobre na relação figura e fundo seu verdadeiro valor ontológico, é porque o fundo não é simplesmente um plano mais afastado de visíveis a partir do qual se destaca a figura atual. Vale dizer, nesse sentido, que o mundo, enquanto fundo ou pressuposto de nossas ações, não é a soma de todas as coisas, mas o horizonte em que elas se dão. Todo visível tem uma latência de sentido que constitui sua visibilidade ou sentido atual: um horizonte de sentido "interior", que representa o sentido da temporalidade inscrito na visibilidade atual, que abre para experiências passadas e ainda por vir, e um horizonte de sentido "exterior", que representa o sentido da espacialidade inscrita na visibilidade atual, que abre para a simultaneidade do mundo 
Fenomenologia e Esquizoanálise na Psicologia: um Encontro Possível?

presente à sua volta. O visível não é, pois, um ser plano ou pontual, dado por inteiro de uma só vez, mas tem um forro invisível que constitui sua visibilidade e dimensão de ser.

O fundo passa a ser, assim, dimensão de deflagração do sentido do Ser. Por isso, se a coesão de nossas vidas ou experiências, e o campo perceptivo que, em última instância, abre para a totalidade do mundo, participam enquanto fundo do sentido atual, não é somente enquanto sentidos presentes ou sedimentados que lhe conferem determinado estilo de mundo e de nós mesmos, mas como dimensões de ser que não podem mais ser fechadas, visto que são forro que sustenta o visível atual.

A noção de fundo nos conduz, assim, a uma nova concepção de filosofia ou do pensamento em geral, pois não podemos colocar o fundo, isto é, a simultaneidade e a duração de nossa experiência de mundo que sustentam nossa visibilidade e pensamento atuais, à nossa frente, o que significaria poder deixar o mundo e a vida para pensá-los. Para destacar seus pressupostos, isto é, assumi-los enquanto figuras de pensamento ou percepção, só podemos fazê-lo apoiando-os ainda na experiência de mundo que os sustenta. Por isso, "o olhar não vence a profundidade, contorna-a” (Merleau-Ponty, 1964/2000a, p. 203).

\section{Deleuze-Merleau-Ponty}

É sabido que, inicialmente, Merleau-Ponty procura encarnar a noção de consciência através da recuperação fenomenológica da experiência do corpo próprio. Que ele tratava, à época, com duas perspectivas de Antropologia na filosofia francesa. De um lado, a filosofia espiritualista, herdeira da noção de cogito, que fazia da consciência e do pensamento a condição de sentido da experiência e, de outro lado, uma ciência experimental que pretendia fundar o sentido da experiência humana nas funções cerebrais, que deviam ser impessoais assim como as explicações da Física. Entre esses dois extremos, que na Filosofia se manifestavam com as noções de em-si e para-si (Sartre), MerleauPonty procurava outra via que tentava reformar as noções de nossa ontologia e de nosso conhecimento. No fundo, tratava-se de conquistar o verdadeiro estatuto da noção de sensibilidade. Como o autor reconhece depois que Fenomenologia da Percepção (Merleau-Ponty, 1945/1994) ainda estava presa à noção 
de consciência, mais precisamente à filosofia da negatividade de Sartre, realiza novos esforços para a descrição do sentido ontológico da nossa experiência originária de mundo. A noção de "carne" é o resultado dessas investigações, e é justamente ela que Deleuze denuncia como uma noção "tenra" e "sensual", que privilegia a presença ou percepção do mundo, em detrimento da atividade que a torna possível.

É nesse sentido, ao menos, que a questão das forças passa a ser fundamental na filosofia de Deleuze. A linguagem não está para dizer o Ser ou a percepção do mundo, mas é uma atividade que, ao lado de outras, dá ordens à vida; ela não revela, é uma pragmática de formação de sentidos a partir da composição com outras forças. Então, a pergunta passa a ser outra: para que serve, quais são seus efeitos, favorecem ou não à vida (Nietzsche) etc. Um livro, dizem Deleuze e Guattari (1980/1995a, pp. 11-12), é uma máquina literária em composição com outras; não é uma interpretação, mas um fazer algo, uma construção, e, portanto, faz parte da composição da realidade.

O que define o poder, segundo Deleuze comentando Foucault - mas também define um corpo em geral, quando Deleuze e Guattari (1980/1997, p. 42) comentam Spinoza -, são relações de forças, que significam a capacidade de afetar e de ser afetado: "o poder de ser afetado é como uma matéria da força, e o poder de afetar é como uma função da força” (Deleuze, 1986/1998, p. 79).

Quando Deleuze e Guattari (1980/1995b, pp. 98-99) falam em máquina abstrata ou diagrama, estão se referindo ao princípio de direção ou organização das forças de determinada sociedade, enquanto puras funções e matérias informes. Quando falam em máquinas ou agenciamentos concretos, estão se referindo às formas em que tais diagramas se concretizam ou se atualizam. Por exemplo, a máquina abstrata ou diagrama de sociedades antigas de Soberania, é definida pelo poder de confiscar ("ação de se apropriar de ações ou produtos, força de confiscar forças" - Deleuze, 1986/1998, p. 91) e de "causar a morte ou deixar viver" (p. 91); a máquina abstrata de uma Sociedade Disciplinar e de Controle, como a nossa, é definida pelas funções "de impor uma tarefa ou comportamento" e de "gerir e controlar a vida" (p. 80). Pode-se falar em diagramas feudal, grego, romano etc. As formas ou estratos em que se atualizam esses diagramas são as instituições ou os espaços sociais, como a Prisão, a Escola, o Hospital, a Família etc. São formas de saber-poder, que podem ser di- 
vididas em formas de expressão e de conteúdo: os enunciados sobre a loucura (formas de expressão), e o médico, o louco e o hospital (formas de conteúdo); os enunciados sobre a delinqüência (formas de expressão), e o juiz, o tribunal, o preso e a prisão (formas de conteúdo) etc. Em síntese, formas de enunciados e de visibilidades que determinam o que se diz e o que se vê. Mas são formas heterogêneas entre si, segundo Deleuze (p. 80), porque os diagramas se atualizam ou tomam forma justamente se diferenciando, e a primeira diferenciação é esta, entre formas de conteúdo e de expressão - ver e dizer -, que se atualizam em diferentes maneiras de ver e de dizer nas instituições do Estado, escolas, hospitais, ruas, praças, famílias etc. Ou seja, as formas de conteúdo e de expressão não são homogêneas, e nem os estratos em que se diferenciam e se atualizam, mas há correspondências entre as duas formas e entre os estratos, invasões, capturas e desarranjos de uns sobre os outros, segundo o movimento das forças ou diagramas que atualizam determinadas estratégias de conjunto.

Por isso os filósofos que falam do Ser como se estivessem descrevendo uma experiência fundamental, na verdade estão compondo com a realidade, ou fazendo uma Vida. Em outros termos, é preciso substituir o verbo "ser" ou o termo "é" pela conjunção "e", que expressa o movimento e a multiplicidade da realidade - o Rizoma (Deleuze \& Guattari, 1980/1995a) -, fazendo-se nas oposições (Deleuze \& Guattari, 1980/1996, pp. 22-29): 1) entre o organismo e o corpo sem órgãos - o corpo sem órgãos não é inimigo dos órgãos, mas do organismo, isto é, da realidade funcional acabada; 2) entre a significância e os movimentos a-significantes que rompem com nossas categorias de significação, não apenas criando novas significações, cujo movimento já se encontra na estrutura significante, em que um signo deve indefinidamente remeter a outro, mas também realizando semióticas a-significantes, composições de sentido que não remetem a nenhum significado que transcende o próprio ato ou que suscitam interpretações; 3) entre subjetividade e dessubjetivação, em que o devir de nossas experiências deve desfazer nossas formações identitárias. A consciência deve, nesse sentido, estar a serviço da experimentação (Deleuze \& Guattari, 1980/1995b, p. 90), e não submetê-la à unidade de experimentação de um "eu"; a unidade do "eu" ("puro" ou empírico) deve ser desfeita na relação com o mundo - é preciso liberar a experimentação como único campo transcendental de sentido. Trata-se de um empirismo radical, em que os nomes reúnem sempre uma multiplicidade de sentidos, que não devem ser sacrifica- 
dos numa unidade substancial redutora. É mais uma maneira cômoda de falar (Deleuze \& Guattari, 1980/1995a, p. 11), ou então, de dizer os acontecimentos - em Deleuze, como em Merleau-Ponty, a imaginação produtora não deve ser sacrificada na unidade do conceito (para falar em termos kantianos).

O corpo-sem-órgãos $(\mathrm{CsO})$ é, na verdade, a criação imanente do próprio desejo, o estado intensivo puro que desterritorializa ou desestratifica para a formação de novos territórios (Deleuze \& Guattari, 1980/1996, p. 13). Nesse sentido, criar um corpo sem órgãos é "uma questão de vida ou de morte, de juventude e de velhice, de tristeza e de alegria. É aí que tudo se decide” (p. 11).

Não há o Ser, mas há o Caos (Deleuze \& Guattari, 1991/1992, p. 59), que são forças de velocidades infinitas que atravessam a Vida em sua composição, vida que já é sempre um princípio de organização do caos. Vislumbramos, pois, o caos, a partir da vida; o caos se encontra na vida, mas não há propriamente experiência pura do caos, o que seria a dissolução da própria vida e, assim, da própria experiência do caos. Ora, a Filosofia enfrenta o caos sem abrir mão do seu Infinito, e tenta sempre traçar, com cada filósofo, um Plano de Imanência com as forças e velocidades infinitas do caos, compô-las, de alguma maneira, dando-lhes consistência. A Filosofia é uma forma de enfrentar e de organizar o caos por meio de Conceitos (que dizem os acontecimentos; é uma composição - de velocidade infinita - das variações que deles participam), enquanto a ciência enfrenta o caos por meio de Funções (composição de variáveis que dizem Estados de Coisas), renunciando ao Infinito a favor de um Plano de Referência (o eixo de coordenadas que define os limites da experiência - "não é a coisa limitada que impõe um limite ao infinito, é o limite que torna possível uma coisa limitada", p. 156). E a arte enfrenta o caos por meio de um Plano de Composição de sensações (percepções e afetos), que também abre para o Infinito. Nesse sentido, toda figura estética construída, isto é, toda composição de forças num bloco de sensações (o monumento artístico) que representa aquilo que Deleuze chama, emprestando os termos de Heidegger, de Casa ou Território, abre para um Universo ou Terra, também presente na composição do bloco, sobretudo nos fundos monocromáticos, que a pintura abstrata explora convocando suas forças (p. 235). As Figuras despóticas ou religiosas também são formas de enfrentar o caos, mas tomam como ponto de partida a transcendência, e não a imanência, como as três formas de pensa- 
mento que são a arte, a filosofia e a ciência. As Figuras são, por princípio, hierárquicas, "descem" sobre a realidade como princípio organizador. Por isso, dizem Deleuze e Guattari (p. 121), se há sentido em se falar em filosofia cristã, só pode ser enquanto produção de Conceitos no plano de imanência, e não enquanto dogmas recebidos (Figuras) - mas todas as formas de pensamento podem se corresponder e se compor de alguma maneira.

Em resumo, não há como fundar o plano de imanência numa Estética, como teria de terminar a Fenomenologia, segundo Deleuze e Guattari (1991/1992, pp. 230-231) - referindo-se à filosofia da "carne" em MerleauPonty -, ou nos Invariantes da Língua, como pretendia o Estruturalismo, a que Deleuze e Guattari (1980/1995b) contrapõem a idéia de linguagem como Pragmática. Porque no princípio não é o Verbo (Significante), o Ser, ou a Carne, mas a Força (sempre plural) que os constitui, e sem ela não há sentido perceptivo ou discursivo propriamente dito. Por isso, Deleuze acusa Heidegger e Merleau-Ponty de uma visão ainda beata ou pacífica demais do Ser (Deleuze, 1986/1998, pp. 119-120) - ou apressada, obliterando a importância da questão das forças em sua formação - e, o Estruturalismo, de uma visão abstrata da Língua (Deleuze \& Guattari, 1980/1995b).

Não cabe aqui discutir a fundo a pertinência dessas críticas, e avaliar em que medida elas se aplicam a uma filosofia (Merleau-Ponty) que prima pela idéia de movimento, invasão e conflito dos corpos na constituição dos sentidos, e que termina numa filosofia da carne em que a noção freudiana de Eros ou de Libido é assumida numa perspectiva ontológica como princípio do movimento de ver e de falar, na tensão ou desequilíbrio entre o "lado de dentro" e o "lado de fora" que permeia o desejo dos corpos (desejo como "busca do interior no exterior e do exterior no interior", e o prazer, "do qual o desejo pode ser ocasião, é a integração do que se vê ao que se faz" - Merleau-Ponty, 1995/2000b, p. 443). Nesse sentido, seria importante investigar na questão das forças, tal como identificada por Deleuze e Guattari, a diferença com a noção de desejo em Merleau-Ponty, ou, mais precisamente, uma vez que Deleuze e Guattari assumem as forças no homem enquanto desejo, investigar a diferença entre as noções de desejo nesses autores, ou entre o movimento que as habita.

Digamos, apenas para referendar provisoriamente a direção da crítica de Deleuze (1986/1998) a ambos (Heidegger e Merleau-Ponty), que, de algu- 
ma forma, Merleau-Ponty sempre procurou por um acordo ou uma passagem de sentido entre ver e dizer, entre a percepção cultural e a percepção bruta ou selvagem do Ser, assim como Heidegger sempre procurou apontar e dizer o sentido do Ser como a diferença daquilo que somos ou pensamos. Ora, para Deleuze e Guattari, todo sentido é construído, e o que os ultrapassa é o caos, isto é, velocidades infinitas de forças - matérias informes e puras funções - na construção de visibilidades e de enunciados, cujas atualizações não são toda a realidade (as forças infinitas), que, por isso, é rizomática ou sempre em devir.

\section{Algumas hipóteses sobre a nossa questão}

Não cabe aqui discutir a fundo a relação das filosofias desses autores, mas gostaríamos de destacar alguns temas relevantes para a Psicologia.

Ambas as filosofias se constituíram como crítica da noção de interioridade, ou da noção clássica de sujeito, e, portanto, apreenderam a subjetividade no mundo. Não pararam de descentralizar a figura do próprio homem, recusando não só a dicotomia entre sujeito e objeto, mas também entre homem e animal, homem e natureza.

Talvez o pensamento de Merleau-Ponty tenha um caráter mais expressivista do que materialista e bélico-estratégico, como têm as filosofias de Foucault e de Deleuze e Guattari. Mas a crítica de Merleau-Ponty à abstração das noções de "consciência", "pensamento" ou "sujeito", herdadas da tradição do pensamento ocidental, abre sua filosofia para o que, à luz do pensamento de Deleuze e Guattari, poderíamos chamar de "materialismo abrangente ou não redutor" (para não confundir com o materialismo vulgar, no mesmo sentido da crítica de Marx a este): não somos ou não nos constituímos apenas com a posse ou a propriedade de bens de consumo (visão de um materialismo vulgar), mas, literalmente, com tudo que vemos, sentimos e fazemos em determinado estilo ou forma de ver, de sentir e de fazer, na relação com outros e o mundo.

Nesse sentido, podemos aproximar a filosofia de Deleuze e Guattari das noções de corpo e de "imaginário" em Merleau-Ponty, por meio das quais, entre outras coisas, os autores procuram romper com o monopólio da linguagem no sentido da experiência, afirmando a promiscuidade de sentidos 
na relação dos corpos entre si, com as coisas ou os animais. Deleuze e Guattari (1980/1996) se opõem fortemente à idéia psicanalítica de desejo enquanto falta, para afirmar a positividade do desejo enquanto fluxo de produção de intensidades - "O CsO é o campo de imanência do desejo, o plano de consistência própria do desejo (ali onde o desejo se define como processo de produção, sem referência a qualquer instância exterior, falta que viria a torná-lo oco, prazer que viria preenchê-lo"(p. 15). Em Merleau-Ponty, o desejo, mais próximo da visão psicanalítica, visa à "supressão" do desequilíbrio instaurado pela abertura do sentido na "carne" - mas ambas as filosofias são herdeiras do campo aberto pelas noções psicanalíticas de sexualidade e inconsciente, a despeito de suas diferenças com a própria Psicanálise.

O pensamento se faz no percebido e na linguagem, e, no entanto, pensar pressupõe algum tipo de abertura, no ver e no dizer, do contrário não haveria o Pensamento.

O pensamento vem sempre do "lado de fora" (as forças do caos), diz Deleuze (1986/1998) comentando Foucault, embora se fazendo sempre no lado de dentro (nos visíveis e enunciados). É sempre um lance de dados, que se faz no interstício de visibilidades e de enunciados já formados. As forças, pois, não se reduzem às suas atualizações nas formas da percepção e da linguagem; o caos está sempre caotizando (Deleuze \& Guattari, 1991/1992, p. 59), ou o excesso das forças está sempre ultrapassando e desorganizando nossas formas de poder e saber, junto às forças que nestas resistem. O pensamento é, pois, sempre uma forma de traçar um plano no caos. Filosofia, ciência e arte são as três formas de pensamento privilegiadas por Deleuze e Guattari, três formas de enfrentar o caos, em que as forças se dobram em suas próprias atualizações. Mas as três formas podem fazer uma má imagem do Pensamento ou do que seja Pensar. A arte pode terminar em clichês de reprodução de opiniões sobre as sensações, e perder sua abertura ao caos, de onde justamente tira seu plano de composição. Mais do que combater o caos, a arte combate as opiniões ou clichês que nos abrigam do caos (p. 262). A ciência também pode substituir sua relação com o caos pelo plano de referência traçado. Em geral, o que impede a ciência de reduzir o plano de imanência atravessado pelo caos (o "lado de fora") ao plano de referência (o lado de dentro) é sua proximidade e enfrentamento constante do caos, que confere dinamismo ao seu pensamento. Mas 
a Filosofia também pode fazer uma má idéia do pensamento e seu plano de imanência, referindo-se a algo de transcendente ao próprio plano de imanência traçado, mesmo que esse transcendente deixe de se referir a algo exterior, e passe a ser buscado na própria imanência, trabalho de toupeira que escava no próprio plano de imanência a sua transcendência (a Urdoxa da Fenomenologia, ou a "carne" em Merleau-Ponty, segundo Deleuze e Guattari). "Cada vez que se interpreta a imanência como 'a' algo, produz-se uma confusão do plano com o conceito, de modo que o conceito se torna um universal transcendente, e o plano, um atributo do conceito" (p. 62). É uma forma de parar e de fixar a Imanência do Pensamento.

A melhor imagem de Pensamento é, pois, a que não confunde o Plano de Imanência como "imanente a algo". A bem da verdade, "O plano de imanência é ao mesmo tempo o que deve ser pensado e o que não pode ser pensado" (p. 78), já que "abarca” o próprio Infinito das forças, a que a Filosofia não pode renunciar quando traça um plano de consistência para o caos e produz uma idéia do pensamento do lado de fora dentro do próprio plano. Por isso,

Talvez seja o gesto supremo da filosofia: não tanto pensar O plano de imanência, mas mostrar que ele esta lá, não pensado em cada plano. O pensar desta maneira, como o fora e o dentro do pensamento, o fora não exterior ou o dentro não interior" (Deleuze e Guattari, 1991/1992, p. 79).

Também em Merleau-Ponty há tentativa de se pensar o Plano de Imanência, que em sua filosofia se chama Ser bruto. O Ser bruto seria análogo ao Caos em Deleuze e Guattari. E assim como o caos só pode aparecer num plano de organização (não há experiência pura do caos), "o ser é o aquilo que exige de nós criação para que dele tenhamos experiência" (Merleau-Ponty, 1964/2000a, p. 187 - tradução modificada). A "carne", que é deiscência de sentido, aparece como movimento da vida inscrito em uma Natureza (Merleau-Ponty, 2000b).

Talvez possamos dizer que, em Merleau-Ponty, a filosofia seja mais uma interrogação contínua sobre nossas condições, e do próprio pensamento, do que a construção de um sistema filosófico, conforme assumida por Deleuze e Guattari, mesmo no sentido de se fazer a melhor imagem do Plano de Imanência. 
A filosofia não é, diz Merleau-Ponty (1965/1984b, p. 190), uma forma de pôr fim aos nossos paradoxos, mas uma maneira de levá-los adiante; ela não resolve as suas questões, como se fosse possível terminá-las em um conhecimento acerca das próprias condições do pensamento, mas é uma interrogação continuada em que a reflexão não pode obturar as condições de sua realização. Por isso fato e essência ou o empírico e o transcendental não são separáveis enquanto condições do pensamento. Não que, misturados na existência, representem os limites do próprio pensamento, mas porque pensar é, justamente, realizar a experiência do mundo no movimento entre um e outro, e não separar pensamento e experiência, atividade e passividade, dicotomias a que nos acostumamos com a distinção entre sujeito e objeto (ou pensamento e objeto na filosofia cartesiana). Encarnado na história, o pensamento se realiza nas vicissitudes da política e do desejo, não como forma impura porque misturada ao sentido dos interesses de outras atividades, pois isso pressuporia a possibilidade, ao menos teórica, de um pensamento puro, quando só há pensamento no movimento da vida, quer dizer, justamente porque encarnado no confronto e na aliança com as coisas e os outros.

Ou, poderíamos dizer com Deleuze e Guattari, somos enredados por muitas forças ou demandas (pensar apenas em nossas forças é uma abstração, pois as forças se definem pelo poder de afetar e ser afetada por outras), mas o importante é encontrar uma composição favorável de forças, uma saída para a vida, expondo à diferença nossas estratificações (sem esquecer as do pensamento e da própria pesquisa); voltar à imanência da experiência (o mais difícil é perceber as coisas pelo meio, isto é, acontecendo, e não segundo definições de origem e finalidade - 1980/1995a, p.35), sabendo guardar doses de estratificações, ou fazendo das estratificações abertura e possibilidade do devir de desejos favoráveis à vida (Deleuze \& Guattari, 1980/1996, pp. 23-24).

Ora, assumindo as perspectivas de pensamento dessas filosofias, qual o significado de se fazer pesquisa em Psicologia? 
Furlan, R. (2006). Phenomenology and schizoanalysis in psychology: a possible concurrence? Psicologia USP, 17(3), 105-126.

\begin{abstract}
Our intent is to put together two important areas of philosophy - phenomenology and schizoanalysis - which exist in the field of psychology as research forms or perspectives. We believe that the critical meeting of these philosophies may be profitable in many ways, from a better understanding of their meanings to a broadening of their usage in the field of psychology.

Index terms: Phenomenology. Schizoanalysis. Merleau-Ponty, Maurice, 1908-1961. Foucault, Michel, 1926-1984. Deleuze, Gilles, 1925-1995.
\end{abstract}

Furlan, R. (2006). La Phénoménologie et la Schizo-analyse dans la Psychologie: un rencontre possible? Psicologia USP, 17(3), 105126.

Résumé: Notre intention c'est d'approcher deux importants domaines de la philosophie qui sont presents dans le domaine de la psychologie comme formes ou perspectives de recherche: la phenomenology et la schizo-analyse. On croit que le rencontre critique de ces deux philosophies puisse apporter différents avantages, non seulement une meilleur compréhension d'elles mêmes mais aussi augmenter l'horizon de leur usage dans de domaine de la psychologie.

Mots clés: Phénoménologie. Schizo-analyse. Merleau-Ponty, Maurice, 1908-1961. Foucault, Michel, 1926-1984. Deleuze, Gilles, 1925-1995.

\title{
Referências
}

Deleuze, G. (2000). Diferença e repetição (L. Orlandi \& R. Machado, trad.). Lisboa: Relógio d'Água. (Trabalho original publicado em 1968)

Deleuze, G. (1998). Foucault. (C. Sant'Anna Martins, trad.). São Paulo: Brasiliense. (Trabalho original publicado em 1986) 
Fenomenologia e Esquizoanálise na Psicologia: um Encontro Possível?

Deleuze, G., \& Guattari, F. (1995a). Mil Platôs - capitalismo e esquizofrenia (A. Guerra Neto, trad., Vol. 1). Rio de Janeiro: Editora 34. (Trabalho original publicado em 1980)

Deleuze, G., \& Guattari, F. (1995b). Mil Platôs - capitalismo e esquizofrenia (A. L. Oliveira \& L. C. Leão, trads., Vol. 2). Rio de Janeiro: Editora 34. (Trabalho original publicado em 1980)

Deleuze, G., \& Guattari, F. (1996). Mil Platôs - capitalismo e esquizofrenia (A. Guerra Neto, A. L. Oliveira, \& L. C. Leão, trads., Vol. 3). Rio de Janeiro: Editora 34. (Trabalho original publicado em 1980)

Deleuze, G., \& Guattari, F. (1997). Mil Platôs - capitalismo e esquizofrenia (S. Rolnik, trad., Vol. 4). Rio de Janeiro: Editora 34. (Trabalho original publicado em 1980)

Deleuze, G., \& Guattari, F. (1992). O que é a filosofia? (B. Prado Jrúnio \& A. A. Muñoz, trads.). Rio de Janeiro: Editora 34. (Trabalho original publicado em 1991)

Foucault, M. (1994a). La pensée du dehors. In D. Defert \& F. Ewald (Orgs.), Dits et écrits I (pp. 518-539). Paris: Gallimard. (Trabalho original publicado em 1966)

Foucault, M. (1994b). Theatrum philosophicum. In D. Defert \& F. Ewald (Orgs.), Dits et écrits II (pp. 75-99). Paris: Gallimard. (Trabalho original publicado em 1970)

Foucault, M. (1999). As palavras e as coisas (S. T. Muchail, trad.). São Paulo: Martins Fontes. (Trabalho original publicado em 1966)

Foucault, M. (2000a). A arqueologia do saber (L. F. B. Neves, trad., 6a ed.). Rio de Janeiro: Forense Universitária. (Trabalho original publicado em 1969)

Foucault, M. (2000b). A ordem do discurso (L. F. de A. Sampaio, trad., 6a ed.) São Paulo: Loyola. (Trabalho original publicado em 1971)

Merleau-Ponty, M. (1984a). O olho e o espírito (M. de S. Chauí, trad.). São Paulo: Abril Cultural. (Trabalho original publicado em 1960)

Merleau-Ponty, M. (1984b). O metafísico no homem (M. de S. Chauí, trad.). São Paulo: Abril Cultural. (Trabalho original publicado em 1965)

Merleau-Ponty, M. (1988). Remarques sur l'usage des donnés psychanalytiques In MerleauPonty à la Sorbonne - Résumés de cours - 1949-1952. Dijon-Quetigny: Cynara.

Merleau-Ponty, M. (1994). Fenomenologia da percepção (C. A. R. de M., trad.). São Paulo: Martins Fontes. (Trabalho original publicado em 1945)

Merleau-Ponty, M. (1996). Notes de cours, 1959-1961 (Texte établi par S. Ménasé). Paris: Gallimard.

Merleau-Ponty, M. (2000a). O visível e o invisível (J. A. Giannotti \& A. M. d'Oliveira, trads.). São Paulo: Perspectiva. (Trabalho original publicado em 1964) 
Merleau-Ponty, M. (2000b). A natureza - Cursos no Collège de France, 1957-1960 (Texto estabelecido e anotado por D. Séglard, Á. Cabral, trad.). São Paulo: Martins Fontes. (Trabalho original publicado em 1995)

Pessoa, F. (2004). Alberto Caeiro. São Paulo: Companhia das Letras. (Trabalho original publicado em 1946)

Proust, M. (1987). No caminho de Swann (M. Quintana, trad., 11a ed.). Rio de Janeiro: Globo. (Trabalho original publicado em 1913)

Sartre, J. P. (1979). Questão de método (B. Prado Júnior, trad.). São Paulo: Difel. (Trabalho original publicado em 1960)

Recebido em: 24.04.2006

Aceito em: 19.06.2006 